\title{
Planar two-stage movable tooth reducer closed by input shaft
}

\author{
Lizhong XU* and Ruixing LI* \\ * Mechanical engineering institute, Yanshan University, Qinhuangdao 066004, China \\ E-mail: xIz@ysu.edu.cn
}

Received: 21 February 2020; Revised: 10 April 2020; Accepted: 27 May 2020

\begin{abstract}
In this paper, a planar two-stage movable tooth reducer closed by input shaft is proposed. Through analyzing the motion transfer flow, the equation for calculating the speed ratio of the reducer is given. From the equation, the tooth numbers for realizing large speed ratio are determined. The power flow of the reducer is analyzed, and the equation of power flow calculation is given by which the conditions for generating closed power are determined. The output torque of the reducer and the force on the meshing pair are investigated, and the changes of the forces on the meshing pair with the parameters are analyzed. The three - dimensional design and motion simulation of the reducer are done which verifies the feasibility of the proposed reducer.
\end{abstract}

Keywords : Two-stage, Movable tooth, Reducer, Closed by input shaft, Force

\section{Introduction}

The joint drive device is a key component widely used in robots, which directly determines the performance of robots. In order to ensure that the robot has good dynamic characteristics and motion accuracy, the driving device is required to have the advantages of high motion accuracy, small sizes, large output torque and high efficiency (Yang, 2019). Harmonic gear reducer is an indispensable part for reliable and accurate operation of light industrial robots (Li, 2009; Vassileva, 2011; Kennedy, 2005).The elastic deformation of the harmonic gear reducer under load could affect the positioning accuracy and dynamic characteristics of the robot. RV reducer is a two-stage reduction drive composed of a planetary gear drive plus a cycloidal pin drive, with high stiffness and rotary accuracy (Mo, 2016). However, its structure is complex, and it is difficult to ensure the accuracy of machining and installation. So it is difficult to realize the miniaturization of the driving device. Therefore, in the efforts to improve the performance of the existing RV reducer and harmonic gear reducer at the same time, it is begun to study and explore a new type of robot joint drive. The movable tooth drive technology has been widely concerned in the world because of its simple structure and processing technology.

In 1982, a drive mechanism with few tooth difference was proposed, which realized deceleration by using the difference between the number of raceway and movable teeth (Keith, 1982). For a movable tooth drive, the motion and stress of the drive were analyzed (Нъезруков, 2009). A two-stage cycloid movable tooth reducer was developed based on the research of single-stage cycloid movable tooth drive (Terada, 2009, 2010, 2016). A ball-rolling type torque transmission device was developed as well (Imase, 2011). A toothless gear drive technology was studied and the toothless reducer developed (Sapsalev, 2012, 2014). Digital design and manufacture technology of a swing movable tooth drive were studied (Yi, 2011). 3D model of a roller movable tooth reducer was fabricated and the vibration characteristics of the reducer was investigated (Wu, 2012). A ball tooth reducer was designed and the contact forces between the balls and meshing elements were investigated using FEM (Nam, 2013). A cycloidal gear reducer of the movable tooth torque limiter was developed and the method for calculating the tooth profile of the cycloidal gear was proposed (Platek, 2016). Nonlinear dynamics of a cycloidal ball planetary transmission considering tooth undercutting was investigated (Yang, 2020). A movable tooth piezoelectric motor was proposed and the chaotic vibration of the motor was investigated $(\mathrm{Li}, 2017)$. An axial sinusoidal movable tooth drive was studied and analyzed whose structure is 
characterized by small radial dimension and large transmission ratio (Xu, 2018, 2019).

The outstanding advantage of the axial sinusoidal movable tooth drive is that the radial dimension is small, which can be used for the driving mechanical arm with limited radial dimension. However, some mechanical arms in the engineering require a large speed ratio reducer with a compact axial size.

Therefore, a planar two-stage tooth reducer closed by input shaft is proposed, which has the advantages of large speed ratio and compact axial size. This reducer has few parts, which is easy to ensure the accuracy of processing and assembly. Similar literature and technical reports about the reducer have not been found yet.

In this paper, for the planar two-stage tooth reducer closed by input shaft, by analyzing the motion transfer flow, the equation for calculating the speed ratio of the reducer is given. Using the equation, the tooth numbers for realizing large speed ratio are determined. The power flow of the reducer is analyzed, and the equation of calculating power flow is given by which the conditions for generating closed power are determined. The output torque of the reducer and the force on the meshing pair are investigated. The three-dimensional design and motion simulation of the reducer are carried out and the feasibility of the proposed reducer is illustrated.

\section{Structure composition and speed ratio}

A planar two-stage movable tooth reducer closed by input shaft is shown in Fig.1. The left end of the wave generator of the driving shaft $\mathrm{H}$ is provided with eccentric circular orbit $\mathrm{H} 1$, and its right end is provided with eccentric circular orbit $\mathrm{H} 2$. Here, the first stage G1 of the movable tooth frame is fixed with the second stage G2 of the movable tooth frame. In the first stage drive, the eccentric circular orbit H1 is input, center ring K1 is fixed, and movable tooth frame G1 is output. In the second stage drive, both eccentric circular orbit H2 and the movable tooth frame G2 are input, and center ring K2 is output. In the closed structure, the first stage of the wave generator is integrated with the second stage of the wave generator which is designed into one element (denotes 10). So, the reducer has highly integrated characteristics, the overall axial size of the reducer is small. In Fig.1b, the eccentricity $a$ and eccentricity error $\Delta a$ are shown (here, for the first stage drive, $a=a_{1}$ and $\Delta a=\Delta a_{1}$; for the second stage drive, $a=a_{2}$ and $\Delta a=\Delta a_{2}$ ).

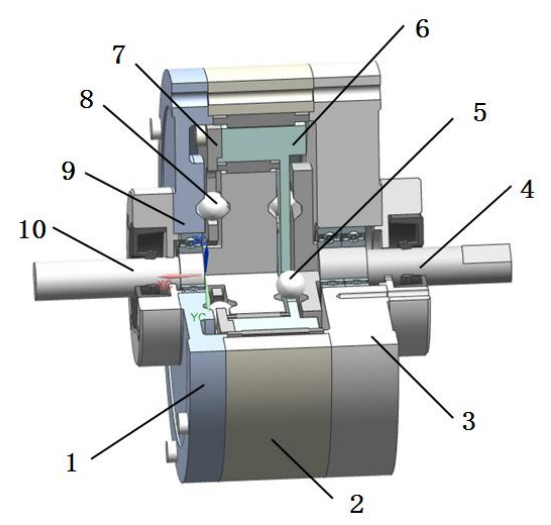

a. 3D sectional view

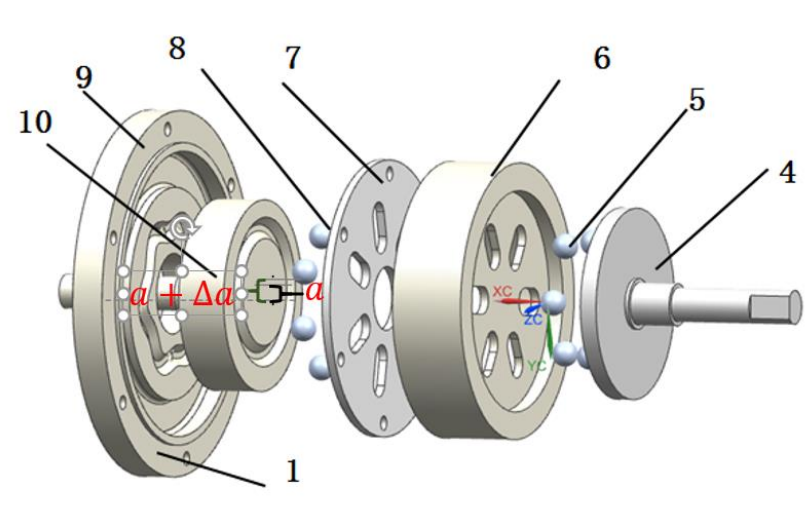

b. Part drawing

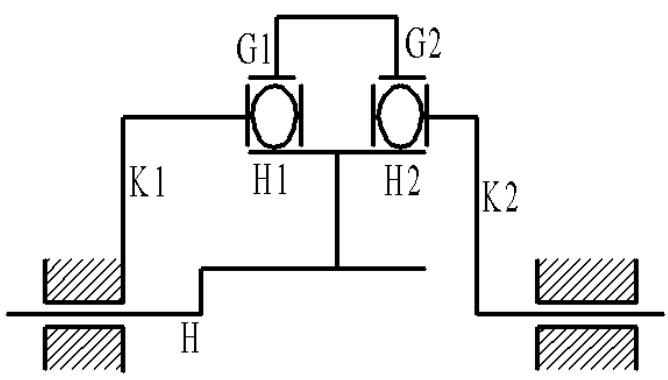

c. Schematic diagram

Fig. 1 Planar two-stage movable tooth reducer closed by driving shaft. 1-the first stage of the center ring K1, 2-outer shell, 3-right shell, 4-the second stage of the center ring K2 (output), 5- the second stage of the ball, 6- the second stage of the movable tooth frame G2, 7- the first stage of the movable tooth frame G1, 8- the first stage of the ball, 9- the first stage of the center ring K1, 10- input shaft. 
As shown as motion diagram and 3D sectional view of the reducer in Fig.1, the first and the second stages of the wave generator are integrated with input shaft. The first and the second stages of the movable tooth frames are integrated with each other. The flow chart of motion transmission of the reducer is shown in Fig. 2.

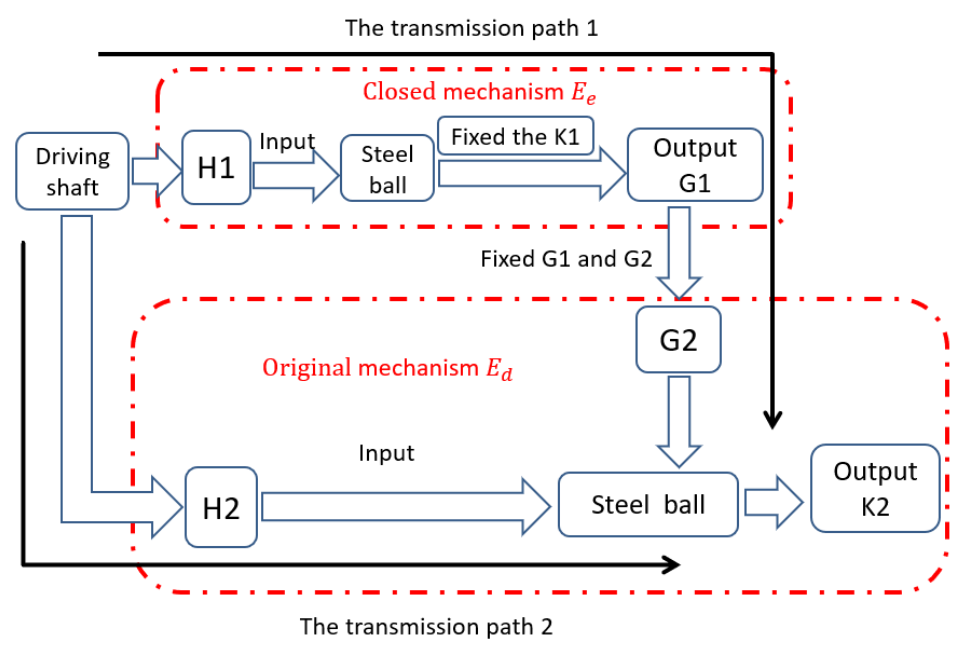

Fig. 2 Motion transmission flow. Input power can be applied to steel balls in the original mechanism $E_{d}$ through the two paths shown in path 1 and path 2 . The path 1 is through closed mechanism $E_{e}$. The path 2 is from driving shaft to the original mechanism $\mathrm{E}_{\mathrm{d}}$ directly.

As shown in the flow chart, the input power can be applied to steel balls in the original mechanism $\mathrm{E}_{\mathrm{d}}$ through the two paths shown in path 1 and path 2 . The two paths are transferred in parallel.

Here, these two paths are considered separately, and then the final speed ratio is solved in parallel. For transmission path 1, the wave generators $\mathrm{H} 1$ and $\mathrm{H} 2$ are separated, and $\mathrm{H} 2$ at the right end is regarded as fixed. For transmission path 2, the movable tooth frames G1 and G2 are separated, and the G2 is regarded as fixed.

(1).Transmission path 1:

In closed mechanism $E_{e}, H 1$ is input, $\mathrm{K} 1$ is fixed, and G1 is output. Thus, movable tooth frames $\mathrm{G} 1$ and $\mathrm{G} 2$ have the same speed. In the original mechanism $E_{d}, H 2$ is fixed, G2 is input and $\mathrm{K} 2$ is output.

In closed mechanism $E_{\mathrm{e}}$, the speed ratio between $\mathrm{H} 1$ and $\mathrm{G} 1$ can be calculated by $i_{11}=\frac{Z_{\mathrm{G} 1}}{Z_{\mathrm{G} 1}-Z_{\mathrm{K} 1}}$. In the original mechanism $E_{\mathrm{d}}$, the speed ratio between $\mathrm{G} 2$ and $\mathrm{K} 2$ can be calculated by $i_{12}=\frac{Z_{\mathrm{K} 2}}{Z_{\mathrm{G} 2}}$. Here, the closed mechanism $\mathrm{E}_{\mathrm{e}}$ and the original mechanism $E_{d}$ are in series state, so the total speed ratio in path 1 is :

$i_{1}=i_{11} \cdot i_{12}=\frac{z_{\mathrm{G} 1}}{Z_{\mathrm{G} 1}-Z_{\mathrm{K} 1}} \cdot \frac{Z_{\mathrm{K} 2}}{z_{\mathrm{G} 2}}$

where $Z_{\mathrm{G} 1}$ is the number of the first step movable teeth, $Z_{\mathrm{K} 1}$ is the orbit period number of the first step center ring, $Z_{\mathrm{G} 2}$ is the number of the second step movable teeth, $Z_{\mathrm{K} 2}$ is the orbit period number of the second step center ring.

(2).Transmission path 2 :

Here, only $\mathrm{H} 2$ is input and $\mathrm{K} 2$ is output. The speed ratio between $\mathrm{H} 2$ and $\mathrm{K} 2$ in original mechanism $\mathrm{E}_{\mathrm{d}}$ is :

$i_{2}=\frac{\mathrm{Z}_{\mathrm{K} 2}}{\mathrm{Z}_{\mathrm{K} 2}-\mathrm{Z}_{\mathrm{G} 2}}$.

As the two paths are transferred in parallel, the speed ratio $i_{\mathrm{s}}$ of the reducer can be calculated as:

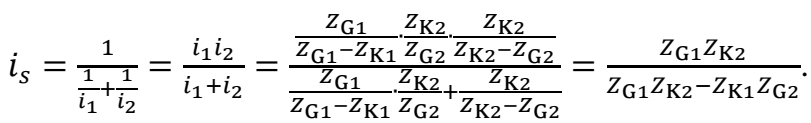

According to Eq. (3), it can be seen that for the two-stage movable tooth reducer closed with input shaft, the number of teeth of each meshing pair should be appropriately selected so that the denominator is equal to one, then a large speed ratio can be obtained. 


\section{Closed power flow}

The close principle of the closed reducer is shown in Fig. 3. Here, X represents steel balls of the second stage drive, $\mathrm{E}$ is closed mechanism. Left eccentric circular orbit $\mathrm{H} 1$ of the wave generator on the input shaft is input of the closed mechanism E. The first stage G1 of the movable tooth frame is output of the closed mechanism E. A differential drive is formed at X. Here, both $\mathrm{G} 2$ and $\mathrm{H} 2$ are input, and the center ring K2 is output.

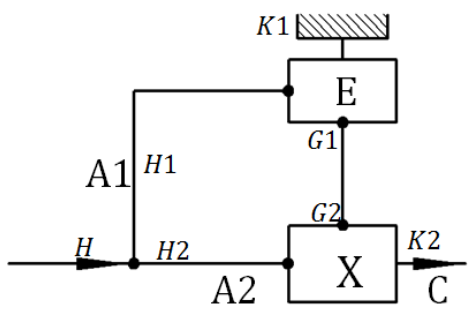

Fig. 3 Close principle of the closed reducer. Here, X represents steel balls of the second stage drive, E is closed mechanism. Left eccentric circular orbit $\mathrm{H} 1$ of the wave generator on the input shaft is input of the closed mechanism $\mathrm{E}$. The first stage G1 of the movable tooth frame is output of the closed mechanism E. A differential drive is formed at X. Here, both $\mathrm{G} 2$ and $\mathrm{H} 2$ are input, and the center ring $\mathrm{K} 2$ is output.

Without considering the power loss, the input power $P_{\mathrm{r}}$ equals the output power $P_{\mathrm{c}}$ : $P_{\mathrm{r}}=P_{\mathrm{C}}$.

According to the relationship between torque and power, it is known:

$P_{\mathrm{A} 1}=P_{\mathrm{r}} \frac{Z_{\mathrm{K} 2}-Z_{\mathrm{G} 2}}{Z_{\mathrm{k} 2}} \frac{\omega_{1}}{\omega_{3}}$

$P_{\mathrm{A} 2}=P_{\mathrm{r}} \frac{Z_{\mathrm{G} 2}}{Z_{\mathrm{K} 2}} \frac{\omega_{2}}{\omega_{3}}$

where $P_{\mathrm{A} 1}$ is power through transmission path $1, P_{\mathrm{A} 2}$ is power through transmission path $2, \omega_{1}$ is angular velocity of input shaft, $\omega_{2}$ is angular velocity of the first step movable tooth frame, $\omega_{3}$ is angular velocity of output shaft.

Substituting $\omega_{1}=\frac{z_{\mathrm{G} 1}}{Z_{\mathrm{G} 1}-Z_{\mathrm{K} 1}} \omega_{2}$ and $\omega_{3}=\frac{Z_{\mathrm{K} 2} Z_{\mathrm{G} 1}-Z_{\mathrm{G} 2} Z_{\mathrm{K} 1}}{Z_{\mathrm{K} 2} Z_{\mathrm{G} 1}} \omega_{1}$ into (5) and (6), yields

$P_{\mathrm{A} 1}=P_{\mathrm{r}} \frac{Z_{\mathrm{K} 2}-Z_{\mathrm{G} 2}}{Z_{\mathrm{K} 2}} \frac{Z_{\mathrm{K} 2} Z_{\mathrm{G} 1}}{Z_{\mathrm{K} 2} Z_{\mathrm{G} 1}-Z_{\mathrm{G} 2} Z_{\mathrm{K} 1}}=P_{\mathrm{r}} \frac{Z_{\mathrm{G} 1}\left(Z_{\mathrm{K} 2}-Z_{\mathrm{G} 2}\right)}{Z_{\mathrm{K} 2} Z_{\mathrm{G} 1}-Z_{\mathrm{G} 2} Z_{\mathrm{K} 1}}$,

$P_{\mathrm{A} 2}=P_{\mathrm{r}} \frac{Z_{\mathrm{G} 2}}{Z_{\mathrm{K} 2}} \frac{\omega_{2}}{\omega_{3}}=P_{\mathrm{r}} \frac{Z_{\mathrm{G} 2}\left(Z_{\mathrm{G} 1}-Z_{\mathrm{K} 1}\right)}{Z_{\mathrm{K} 2} Z_{\mathrm{G} 1}-Z_{\mathrm{G} 2} Z_{\mathrm{K} 1}}$.

From Eqs. (7) and (8), it is known:

(1) At $Z_{\mathrm{K} 2} Z_{\mathrm{G} 1}>Z_{\mathrm{K} 1} Z_{\mathrm{G} 2}$ :

If $Z_{\mathrm{G} 1}>Z_{\mathrm{K} 1}$ and $Z_{\mathrm{K} 2}>Z_{\mathrm{G} 2}, P_{\mathrm{A} 1}>0$ and $P_{\mathrm{A} 2}>0$, there is no closed power.

If $Z_{\mathrm{G} 1}>Z_{\mathrm{K} 1}$ and $Z_{\mathrm{K} 2}<Z_{\mathrm{G} 2}, P_{\mathrm{A} 2}>0$ and $P_{\mathrm{A} 1}<0$, there is closed power which is equal to $\left|P_{\mathrm{A} 1}\right|$.

If $\mathrm{Z}_{\mathrm{G} 1}<\mathrm{Z}_{\mathrm{K} 1}$ and $\mathrm{Z}_{\mathrm{K} 2}>\mathrm{Z}_{\mathrm{G} 2}, \mathrm{P}_{\mathrm{A} 2}<0$ and $\mathrm{P}_{\mathrm{A} 1}>0$, there is closed power which is equal to $\left|P_{\mathrm{A} 2}\right|$.

(2) At $Z_{\mathrm{K} 2} Z_{\mathrm{G} 1}<Z_{\mathrm{K} 1} Z_{\mathrm{G} 2}$ :

If $Z_{\mathrm{G} 1}>Z_{\mathrm{K} 1}$ and $Z_{\mathrm{K} 2}<Z_{\mathrm{G} 2}, P_{\mathrm{A} 2}<0$ and $P_{\mathrm{A} 1}>0$, there is closed power which is equal to $\left|P_{\mathrm{A} 2}\right|$.

If $Z_{\mathrm{G} 1}<Z_{\mathrm{K} 1}$ and $Z_{\mathrm{K} 2}>Z_{\mathrm{G} 2}, P_{\mathrm{A} 2}>0$ and $P_{\mathrm{A} 1}<0$, there is closed power which is equal to $\left|P_{\mathrm{A} 1}\right|$.

If $Z_{\mathrm{G} 1}<Z_{\mathrm{K} 1}$ and $Z_{\mathrm{K} 2}<Z_{\mathrm{G} 2}, P_{\mathrm{A} 1}>0$ and $P_{\mathrm{A} 2}>0$, there is no closed power.

Using above equations, the closed power and speed ratio for different tooth numbers are calculated (see Table 1, here $Z_{\mathrm{H} 1}$ and $Z_{\mathrm{H} 2}$ are the orbit period number of the first and second step wave generator, respectively). It shows:

In the closed reducer, the tooth number $Z_{\mathrm{G} 1}, Z_{\mathrm{K} 1}, Z_{\mathrm{G} 2}$ and $Z_{\mathrm{K} 2}$ can be reasonably selected to obtain large speed ratio or zero closed power. However, when the speed ratio is large, the closed power is also large, resulting in low operating efficiency of the reducer when considering the power loss. Based on the above analysis, this type of closed planar two-stage movable tooth reducer should be used in the case that the speed ratio is relatively large, and the relative space size is small and the high efficiency is not required.

Table 1 closed power and speed ratio for different tooth numbers 


\begin{tabular}{|c|c|c|c|c|c|c|c|c|c|}
\hline \multicolumn{3}{|c|}{ Stage one } & \multicolumn{3}{|c|}{ Stage two } & \multirow{2}{*}{$\begin{array}{l}\text { Speed } \\
\text { ratio }\end{array}$} & \multicolumn{3}{|c|}{ power $\left(* P_{\mathrm{c}}\right)$} \\
\hline$Z_{\mathrm{H} 1}$ & $Z_{\mathrm{K} 1}$ & $Z_{\mathrm{G} 1}$ & $Z_{\mathrm{H} 2}$ & $Z_{\mathrm{G} 2}$ & $Z_{\mathrm{K} 2}$ & & $P_{\mathrm{A} 1}$ & $P_{\mathrm{A} 2}$ & $\begin{array}{l}\text { Closed } \\
\text { power }\end{array}$ \\
\hline 1 & 6 & 7 & 1 & 6 & 7 & $49 / 13$ & $7 / 13$ & $6 / 13$ & 0 \\
\hline 1 & 6 & 7 & 1 & 7 & 6 & - & - & - & - \\
\hline 1 & 6 & 7 & 1 & 5 & 6 & $7 / 2$ & $7 / 12$ & $5 / 12$ & 0 \\
\hline 1 & 6 & 7 & 1 & 6 & 5 & -35 & 7 & -6 & 6 \\
\hline 1 & 6 & 7 & 1 & 4 & 5 & $35 / 11$ & $7 / 11$ & $4 / 11$ & 0 \\
\hline 1 & 6 & 7 & 1 & 5 & 4 & -14 & $7 / 2$ & $-5 / 2$ & $5 / 2$ \\
\hline 1 & 7 & 6 & 1 & 6 & 7 & - & - & - & - \\
\hline 1 & 7 & 6 & 1 & 7 & 6 & $-36 / 13$ & $6 / 13$ & $7 / 13$ & 0 \\
\hline 1 & 7 & 6 & 1 & 5 & 6 & 36 & 6 & -5 & 5 \\
\hline 1 & 7 & 6 & 1 & 6 & 5 & $-5 / 2$ & $1 / 2$ & $1 / 2$ & 0 \\
\hline 1 & 7 & 6 & 1 & 4 & 5 & 15 & 3 & -2 & 2 \\
\hline 1 & 7 & 6 & 1 & 5 & 4 & $-24 / 11$ & $6 / 11$ & $5 / 11$ & 0 \\
\hline
\end{tabular}

\section{Torque and forces}

Figure 4 gives forces on a movable tooth of the reducer. Here, $F_{\mathrm{si}}$ denotes the force from movable tooth frame G1, $F_{\mathrm{gi}}$ denotes the projection (in the radial plane) of the force from center ring $\mathrm{K} 1$, and $F_{\mathrm{ji}}$ denotes the projection (in the radial plane) of the force from wave generator $\mathrm{H} 1$.

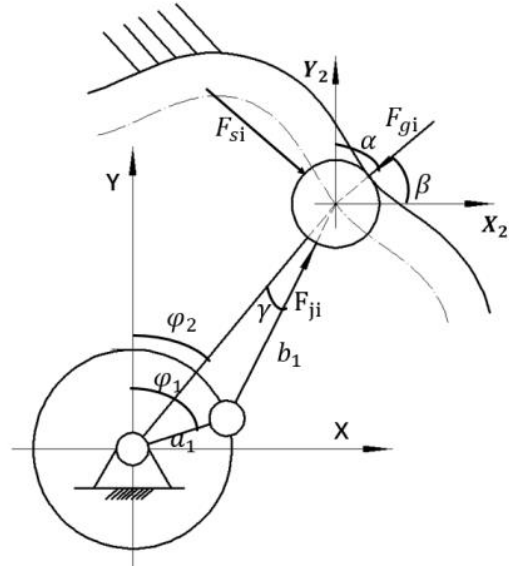

a) forces on movable tooth

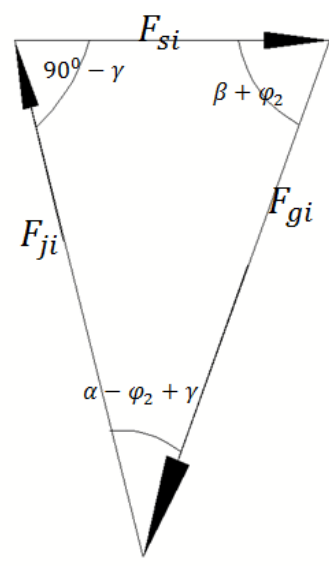

b). geometric relation of forces

Fig. 4 Forces on a movable tooth of the reducer. Here, $F_{\mathrm{si}}$ denotes the force from movable tooth frame G1, $F_{\mathrm{gi}}$ denotes the projection (in the radial plane) of the force from center ring $\mathrm{K} 1$, and $F_{\mathrm{ji}}$ denotes the projection (in the radial plane) of the force from wave generator $\mathrm{H} 1$.

Torque balance relationship in the reducer is

$T_{\mathrm{A} 1}+T_{\mathrm{A} 2}=T_{\mathrm{em}}$,

where $T_{\mathrm{em}}$ is the torque from input shaft; $T_{\mathrm{A} 1}$ is the torque applied to wave generator by the steel ball in orbit $\mathrm{H} 1$; $T_{\mathrm{A} 2}$ is the torque applied to wave generator by the steel ball in orbit $\mathrm{H} 2$.

According to the relationship between transmission power and speed ratio, output torque $T_{\mathrm{c}}$ can be known as follows:

$T_{\mathrm{C}}=\frac{z_{\mathrm{K} 2} z_{\mathrm{G} 1}}{Z_{\mathrm{K} 2} Z_{\mathrm{G} 1}-Z_{\mathrm{K} 1} z_{\mathrm{G} 2}} T_{\mathrm{em}}$,

and

$T_{\mathrm{A} 1}=\frac{z_{\mathrm{G} 1}\left(Z_{\mathrm{K} 2}-Z_{\mathrm{G} 2}\right)}{Z_{\mathrm{K} 2} z_{\mathrm{G} 1}-Z_{\mathrm{K} 1} z_{\mathrm{G} 2}} T_{\mathrm{em}}$,

$T_{\mathrm{A} 2}=\frac{Z_{\mathrm{G} 2}\left(Z_{\mathrm{G} 1}-Z_{\mathrm{K} 1}\right)}{Z_{\mathrm{K} 2} z_{\mathrm{G} 1}-Z_{\mathrm{K} 1} z_{\mathrm{G} 2}} T_{\mathrm{em}}$. 
In the transmission process, half of the steel ball is in the up motion and half of the steel ball is in the down motion.

When the steel ball number $n_{1}$ is odd, one steel ball is in the middle position, then $\left(n_{1}-1\right) / 2$ steel balls are in the upper motion, while $\left(n_{1}-1\right) / 2$ steel balls are in the lower motion. Here, $n_{1}$ is the number of steel balls. According to the motion characteristics of eccentric circle, the steel balls in the upper motion are adjacent to each other, and the steel balls in the lower motion are adjacent to each other as well.

The torque from the steel ball in the middle position is calculated as:

$T_{\mathrm{A} 1 \mathrm{z}}=\sum_{\mathrm{j}=1}^{1} F_{\mathrm{ji}} S_{\mathrm{c} 1} \sin \gamma_{1}$

where $S_{\mathrm{c} 1}$ is distance between central ring center and movable tooth center, $s_{\mathrm{c} 1}=s_{\mathrm{c} 1 \mathrm{~s}}$ for the upper motion, and $s_{\mathrm{c} 1}=$ $s_{\mathrm{c} 1 \mathrm{x}}$ for the lower motion, see below.

It is assumed that the steel balls from 2 to $\left(\mathrm{n}_{1}-1\right) / 2$ are in the upper motion. The torque from these steel balls is: $T_{\mathrm{A} 1 \mathrm{~s}}=\sum_{\mathrm{i}=2}^{\mathrm{n}_{1 \mathrm{z}}} F_{\mathrm{ji}} S_{\mathrm{c} 1 \mathrm{~s}} \sin \gamma_{1}$

where $S_{\mathrm{c} 1 \mathrm{~s}}=a_{1} \cos Z_{\mathrm{K} 1} \varphi_{2 \mathrm{i}}+\sqrt{\left(b_{1}-r \cos \beta\right)^{2}-a_{1}^{2} \sin ^{2} Z_{\mathrm{K} 1} \varphi_{2 \mathrm{i}}}, \mathrm{n}_{1 \mathrm{z}}=\frac{n_{1}-1}{2} ; \beta$ is angle between the inclined plane and axis of eccentric circular track.

It is assumed that the steel balls from $\left(\mathrm{n}_{1}-1\right) / 2$ to $\mathrm{n}_{1}$ are in the lower motion. The torque from these steel balls is:

$T_{\mathrm{A} 1 \mathrm{x}}=\sum_{\mathrm{i} 1 \mathrm{n}_{1 \mathrm{z}}}^{\mathrm{n} 1} F_{\mathrm{ji}} S_{\mathrm{c} 1 \mathrm{x}} \sin \gamma_{1}$,

where $S_{\mathrm{c} 1 \mathrm{x}}=a_{1} \cos Z_{\mathrm{K} 1} \varphi_{2 \mathrm{i}}+\sqrt{\left(b_{1}+r \cos \beta\right)^{2}-a_{1}^{2} \sin ^{2} Z_{\mathrm{K} 1} \varphi_{2 \mathrm{i}}}$.

Thus, the total torque is:

$T_{\mathrm{A} 1}=T_{\mathrm{A} 1 \mathrm{z}}+T_{\mathrm{A} 1 \mathrm{x}}+T_{\mathrm{A} 1 \mathrm{~s}}$.

The relationship between the radial force $F_{\mathrm{ji}}$ and its maximum value $F_{\mathrm{jimax}}$ is

$F_{\mathrm{ji}}=\frac{F_{\mathrm{jimax}}}{\lambda_{1}}\left(\cos Z_{\mathrm{K} 1} \varphi_{2 \mathrm{i}}+\sqrt{\lambda_{1}^{2}-\sin ^{2} Z_{\mathrm{K} 1} \varphi_{2 \mathrm{i}}}\right) \sin Z_{\mathrm{K} 1} \varphi_{2 \mathrm{i}}$,

where $\sin \gamma_{1}=\frac{\sin \left(Z_{\mathrm{K} 1} \varphi_{2}\right)}{\lambda_{1}}$ and $\lambda_{1}=\frac{b_{1}}{a_{1}}$.

Substituting Eqs. (11)-(14) into (15), yields

$F_{\text {jimax }}=\frac{T_{\mathrm{A} 1} \lambda_{1}^{2}}{Z_{\mathrm{t} 1}}$,

where $Z_{\mathrm{t} 1}=Z_{\mathrm{t} 1 \mathrm{z}}+Z_{\mathrm{t} 1 \mathrm{~s}}+Z_{\mathrm{t} 1 \mathrm{x}}$;

$$
\begin{gathered}
Z_{\mathrm{t} 1 \mathrm{z}}=\left(\cos Z_{\mathrm{K} 1} \varphi_{2 \mathrm{i}}+\sqrt{\lambda_{1}^{2}-\sin ^{2} Z_{\mathrm{K} 1} \varphi_{2 \mathrm{i}}}\right) \sin ^{2} Z_{\mathrm{K} 1} \varphi_{2 \mathrm{i}} S_{\mathrm{c} 1} \\
Z_{\mathrm{t} 1 \mathrm{~s}}=\sum_{\mathrm{i}=2}^{\mathrm{n}_{1 \mathrm{z}}}\left(\cos Z_{\mathrm{K} 1} \varphi_{2 \mathrm{i}}+\sqrt{\lambda_{1}^{2}-\sin ^{2} Z_{\mathrm{K} 1} \varphi_{2 \mathrm{i}}}\right) \sin ^{2} Z_{\mathrm{K} 1} \varphi_{2 \mathrm{i}}\left(S_{\mathrm{c} 1}-r \cos \beta\right) \\
Z_{\mathrm{t} 1 \mathrm{x}}=\sum_{\mathrm{i}=\mathrm{n}_{1 \mathrm{z}}}^{\mathrm{n} 1}\left(\cos Z_{\mathrm{K} 1} \varphi_{2 \mathrm{i}}+\sqrt{\lambda_{1}^{2}-\sin ^{2} Z_{\mathrm{K} 1} \varphi_{2 \mathrm{i}}}\right) \sin ^{2} Z_{\mathrm{K} 1} \varphi_{2 \mathrm{i}}\left(S_{\mathrm{c} 1}+r \cos \beta\right) .
\end{gathered}
$$

From Fig. 4, it is known:

$$
\begin{aligned}
& F_{\mathrm{si}}=\left(\frac{i_{1}}{\lambda_{1}} \sin Z_{\mathrm{K} 1} \varphi_{2 \mathrm{i}}\right) F_{\mathrm{ji}}, \\
& F_{\mathrm{gi}}=\left(\frac{1}{\lambda_{1}} \sqrt{\left(Z_{\mathrm{K} 1}^{2}-1\right) \sin Z_{\mathrm{K} 1} \varphi_{2 \mathrm{i}}+\lambda_{1}^{2}}\right) F_{\mathrm{ji}} .
\end{aligned}
$$

Considering that the inclination angle $\beta$, the forces on the movable tooth $i$ in the first-stage drive can be obtained as follows:

$$
\left\{\begin{array}{c}
F_{1 \mathrm{i}}=\frac{T_{\mathrm{A} 1} \lambda_{1}}{Z_{\mathrm{t} 1} \sin \beta}\left(\cos Z_{\mathrm{K} 1} \varphi_{2 \mathrm{i}}+\sqrt{\lambda_{1}^{2}-\sin ^{2} Z_{\mathrm{K} 1} \varphi_{2 \mathrm{i}}}\right) \sin Z_{\mathrm{K} 1} \varphi_{2 \mathrm{i}} \\
F_{2 \mathrm{i}}=\frac{T_{\mathrm{A} 1} i_{1}}{Z_{\mathrm{t} 1}}\left(\cos Z_{\mathrm{K} 1} \varphi_{2 \mathrm{i}}+\sqrt{\lambda_{1}^{2}-\sin ^{2} Z_{\mathrm{K} 1} \varphi_{2 \mathrm{i}}}\right) \sin ^{2} Z_{\mathrm{K} 1} \varphi_{2 \mathrm{i}} \\
F_{3 \mathrm{i}}=\frac{T_{\mathrm{A} 1}}{Z_{\mathrm{t} 1} \sin \beta} \sin Z_{\mathrm{K} 1} \varphi_{2 \mathrm{i}}\left(\cos Z_{\mathrm{K} 1} \varphi_{2 \mathrm{i}}+\sqrt{\lambda_{1}^{2}-\sin ^{2} Z_{\mathrm{K} 1} \varphi_{2 \mathrm{i}}}\right) \sqrt{\left(Z_{\mathrm{K} 1}^{2}-1\right) \sin Z_{\mathrm{K} 1} \varphi_{2 \mathrm{i}}+\lambda_{1}^{2}}
\end{array}\right.
$$

Considering the influence of generator eccentricity error, the force equations of the drive system are derived as follows. Here, the true eccentricity of the generator is $a_{1 p}=a_{1}+\Delta a$. As the eccentricity of the wave generator is 
offset, contact elastic deformation will occur between meshing parts in the transmission process. Let the force perpendicular to the surface of the wave generator caused by the eccentric error be $F_{\text {jip }}$, the force perpendicular to the surface of the center ring caused by the eccentric error be $F_{\text {gip }}$, the force perpendicular to the surface of the movable tooth frame caused by the eccentric error be $F_{\text {sip. }}$ The geometric relationship of the three forces is the same as that in Fig. 4b. The elastic deformation distribution of the steel ball along the entire track can be considered to be $\delta=\Delta a \sin \theta$. Thus, the elastic deformation coordination condition between the steel balls is

$\frac{F_{j i p}}{F_{\text {jipmax }}}=\frac{\Delta a \sin \theta}{\Delta a}=\sin \theta$,

where $F_{\text {jipmax }}$ is the maximum force between generator and ball at the point corresponding to the maximum elastic deformation.

According to the Hertz formula of elastic contact deformation, the maximum deformation of the ball can be determined

$\delta_{\max }=\Delta a=1.231 \sqrt[3]{\left(\frac{F_{\mathrm{jipmax}}}{E}\right)^{2}} \frac{1}{r}$.

Combining Eq.(20) with(21), yields

$F_{\text {jip }}=E \sqrt{r\left(\frac{\Delta a}{1.231}\right)^{3}} \sin \theta$.

Because the geometric relationship of the three forces $F_{\text {jp }}, F_{\text {gip }}$ and $F_{\text {sip }}$ is the same as that in Fig. $4 b$, substituting Eq.(22) into (17) and (18), yields

$$
\begin{aligned}
& F_{\text {sip }}=\frac{i_{1}}{\lambda_{1}} \sin Z_{\mathrm{K} 1} \varphi_{2 \mathrm{i}} F_{\mathrm{jip}}=\frac{E i_{1} \sin Z_{\mathrm{K} 1} \varphi_{2 \mathrm{i}} \sin \theta}{\lambda_{1}} \sqrt{r\left(\frac{\Delta a}{1.231}\right)^{3}}, \\
& F_{\text {gip }}=\left(\frac{1}{\lambda_{1}} \sqrt{\left(Z_{K 1}^{2}-1\right) \sin Z_{K 1} \varphi_{2 i}+\lambda_{1}^{2}}\right) F_{\mathrm{jip}}=\frac{E \sqrt{\left[\left(Z_{K 1}^{2}-1\right) \sin Z_{K 1} \varphi_{2 i}+\lambda_{1}^{2}\right] r\left(\frac{\Delta a}{1.231}\right)^{3}}}{\lambda_{1}} \sin \theta .
\end{aligned}
$$

The total force applied to wave generator is

$F_{\mathrm{jih}}=F_{\mathrm{ji}}+F_{\mathrm{jip}}=\frac{F_{\mathrm{jimax}}}{\lambda_{1}}\left(\cos Z_{K 1} \varphi_{2 i}+\sqrt{\lambda_{1}^{2}-\sin ^{2} Z_{K 1} \varphi_{2 i}}\right) \sin Z_{K 1} \varphi_{2 i}+E \sqrt{r\left(\frac{\Delta a}{1.231}\right)^{3}} \sin \theta$.

The torque from the steel ball in the middle position is calculated as

$T_{A 1 z p}=\left(F_{\mathrm{ji}}+F_{\mathrm{jip}}\right) S_{\mathrm{c} 1} \sin \gamma_{1}$,

It is assumed that the steel balls from 2 to (n1-1)/2 are in the upper motion. The torque from these steel balls is $T_{A 1 s p}=\sum_{i=2}^{n_{1 z}}\left(F_{\mathrm{ji}}+F_{\mathrm{jip}}\right) S_{c 1 \mathrm{~s}} \sin \gamma_{1}$,

It is assumed that the steel balls from (n1-1)/2 to $\mathrm{n} 1$ are in the lower motion. The torque from these steel balls is: $T_{A 1 x p}=\sum_{i=n_{1 z}}^{n 1}\left(F_{\mathrm{ji}}+F_{\mathrm{jip}}\right) S_{\mathrm{c} 1 \mathrm{x}} \sin \gamma_{1}$,

Thus, the total torque is

Combining Eq.(29) with (25)-(28), yields

$$
\mathrm{T}_{\mathrm{A} 1}=\mathrm{T}_{\mathrm{A} 1 \mathrm{zp}}+\mathrm{T}_{\mathrm{A} 1 \mathrm{xp}}+\mathrm{T}_{\mathrm{A} 1 \mathrm{sp}}
$$

$$
F_{\text {jimax }}=\frac{\left(T_{A 1}-T_{p}\right) \lambda_{1}^{2}}{Z_{t 1}}
$$

where

$T_{\mathrm{p}}=$

$\frac{E}{\lambda_{1}}\left(\sqrt{r\left(\frac{\Delta a}{1.231}\right)^{3}} \mathrm{~S}_{\mathrm{c} 1} \sin \theta \sin Z_{K 1} \varphi_{2 i}+\sum_{\mathrm{i}=2}^{\mathrm{n}_{1 \mathrm{z}}} \sqrt{r\left(\frac{\Delta a}{1.231}\right)^{3}} \mathrm{~S}_{\mathrm{c} 1 \mathrm{~s}} \sin \theta \sin Z_{K 1} \varphi_{2 i}+\sum_{\mathrm{i}=\mathrm{n}_{1 \mathrm{z}}}^{\mathrm{n} 1} \sqrt{r\left(\frac{\Delta a}{1.231}\right)^{3}} \mathrm{~S}_{\mathrm{c} 1 \mathrm{x}} \sin \theta \sin Z_{K 1} \varphi_{2 i}\right)$.

Thus

$$
\begin{aligned}
F_{\mathrm{ji}} & =\frac{\left(T_{A 1}-T_{p}\right) \lambda_{1}}{Z_{t 1}}\left(\cos \mathrm{Z}_{\mathrm{K} 1} \varphi_{2 \mathrm{i}}+\sqrt{\lambda_{1}^{2}-\sin ^{2} \mathrm{Z}_{\mathrm{K} 1} \varphi_{2 \mathrm{i}}}\right) \sin _{\mathrm{K} 1} \varphi_{2 \mathrm{i}}, \\
F_{\mathrm{Si}} & =\frac{\left(T_{A 1}-T_{p}\right) \mathrm{i}_{1}}{Z_{t 1}}\left(\cos \mathrm{Z}_{\mathrm{K} 1} \varphi_{2 \mathrm{i}}+\sqrt{\lambda_{1}^{2}-\sin ^{2} \mathrm{Z}_{\mathrm{K} 1} \varphi_{2 \mathrm{i}}}\right) \sin ^{2} \mathrm{Z}_{\mathrm{K} 1} \varphi_{2 \mathrm{i}}, \\
F_{\mathrm{gi}} & =\frac{\left(T_{A 1}-T_{p}\right)}{Z_{t 1}}\left(\cos \mathrm{Z}_{\mathrm{K} 1} \varphi_{2 \mathrm{i}}+\sqrt{\lambda_{1}^{2}-\sin ^{2} \mathrm{Z}_{\mathrm{K} 1} \varphi_{2 \mathrm{i}}}\right) \sqrt{\left(\mathrm{Z}_{\mathrm{K} 1}^{2}-1\right) \sin _{\mathrm{K} 1} \varphi_{2 \mathrm{i}}+\lambda_{1}^{2}} \sin Z_{\mathrm{K} 1} \varphi_{2 \mathrm{i}} .
\end{aligned}
$$

Considering generator eccentricity error, the forces on the movable tooth $i$ in the first-stage drive are: 
$F_{1 \mathrm{i}}=\frac{F_{\mathrm{ji}}+F_{\mathrm{jip}}}{\sin \beta}$,

$F_{2 \mathrm{i}}=F_{\mathrm{si}}+F_{\mathrm{sip}}$,

$F_{3 \mathrm{i}}=\frac{F_{\mathrm{gi}}+F_{\text {gip }}}{\sin \beta}$.

For the second stage drive, the steel ball number is even, half of the steel balls are in the upper motion, while half of the steel balls are in the lower motion. Here, $\mathrm{n}_{2}$ is the number of steel balls.

It is assumed that the steel balls from 1 to $\mathrm{n}_{2 \mathrm{z}}$ are in the upper motion. The torque from these steel balls is:

$T_{\mathrm{A} 2 \mathrm{~s}}=\sum_{\mathrm{j}=2}^{\mathrm{n}_{2 \mathrm{z}}} F_{\mathrm{jj}} S_{\mathrm{c} 2 \mathrm{~s}} \sin \gamma_{2}$,

where $S_{\mathrm{c} 2 \mathrm{~s}}=a_{2} \cos Z_{\mathrm{K} 2} \varphi_{2 \mathrm{j}}+\sqrt{\left(b_{2}-r \cos \beta\right)^{2}-a_{2}^{2} \sin ^{2} Z_{\mathrm{K} 2} \varphi_{2 \mathrm{j}}}$.

Then, the steel balls from $\mathrm{n}_{2 z}$ to $\mathrm{n}_{2}$ are in the lower motion. The torque from these steel balls is:

$T_{\mathrm{A} 2 \mathrm{x}}=\sum_{\mathrm{j}=2 \mathrm{z}}^{\mathrm{n}_{2}} F_{\mathrm{jj}} S_{\mathrm{c} 2 \mathrm{x}} \sin \gamma_{2}$,

where $S_{\mathrm{c} 2 \mathrm{x}}=a_{2} \cos Z_{\mathrm{K} 2} \varphi_{2 \mathrm{j}}+\sqrt{\left(b_{2}+r \cos \beta\right)^{2}-a_{2}^{2} \sin ^{2} Z_{\mathrm{K} 2} \varphi_{2 \mathrm{j}}}$.

In a same manner, yielding :

$F_{\mathrm{jjmax}}=\frac{T_{\mathrm{A} 2} \lambda_{2}^{2}}{Z_{\mathrm{t} 2}}$,

where $Z_{\mathrm{t} 2}=Z_{\mathrm{t} 2 \mathrm{~s}}+Z_{\mathrm{t} 2 \mathrm{x}}$.

The radial force on $j$-th steel ball is

$F_{\mathrm{jj}}=\frac{F_{\mathrm{jjmax}}}{\lambda_{2}}\left(\cos Z_{\mathrm{K} 2} \varphi_{2 \mathrm{j}}+\sqrt{\lambda_{1}^{2}-\sin ^{2} Z_{\mathrm{K} 2} \varphi_{2 \mathrm{j}}}\right) \sin Z_{\mathrm{K} 2} \varphi_{2 \mathrm{j}}$,

where $Z_{\mathrm{t} 2 \mathrm{~s}}=\sum_{\mathrm{j}=1}^{\mathrm{n}_{2 \mathrm{z}}}\left(\cos Z_{\mathrm{K} 2} \varphi_{2 \mathrm{j}}+\sqrt{\lambda_{2}^{2}-\sin ^{2} Z_{\mathrm{K} 2} \varphi_{2 \mathrm{j}}}\right) \sin ^{2} Z_{\mathrm{K} 2} \varphi_{2 \mathrm{j}}\left(S_{\mathrm{c} 2}-r \cos \beta\right)$;

$Z_{\mathrm{t} 2 \mathrm{x}}=\sum_{\mathrm{j}=\mathrm{n}_{2 \mathrm{Z}}}^{\mathrm{n} 2}\left(\cos Z_{\mathrm{K} 2} \varphi_{2 \mathrm{j}}+\sqrt{\lambda_{2}^{2}-\sin ^{2} Z_{\mathrm{K} 2} \varphi_{2 \mathrm{j}}}\right) \sin ^{2} Z_{\mathrm{K} 2} \varphi_{2 \mathrm{j}}\left(S_{\mathrm{c} 2}+r \cos \beta\right)$.

From Fig. 4, it is known:

$F_{\mathrm{sj}}=\left(\frac{i_{2}}{\lambda_{2}} \sin Z_{\mathrm{K} 2} \varphi_{2 \mathrm{j}}\right) F_{\mathrm{jj}}$,

$F_{\mathrm{gj}}=\left(\frac{1}{\lambda_{2}} \sqrt{\left(Z_{\mathrm{K} 2}^{2}-1\right) \sin Z_{\mathrm{K} 2} \varphi_{2 \mathrm{j}}+\lambda_{2}^{2}}\right) F_{\mathrm{jj}}$.

Considering that the inclination angle $\beta$, the forces on the movable tooth $\mathrm{j}$ in the second-stage drive can be obtained as follows:

$$
\left\{\begin{array}{l}
F_{1 \mathrm{j}}=\frac{2 T_{\mathrm{A} 2} \lambda_{2}}{\left(Z_{\mathrm{t} 2 \mathrm{~s}}+Z_{\mathrm{t} 2 \mathrm{x}}\right) \sin \beta}\left(\cos Z_{\mathrm{K} 2} \varphi_{2 \mathrm{j}}+\sqrt{\lambda_{2}^{2}-\sin ^{2} Z_{\mathrm{K} 2} \varphi_{2 \mathrm{j}}}\right) \sin Z_{\mathrm{K} 2} \varphi_{2 \mathrm{j}} \\
F_{2 \mathrm{j}}=\frac{2 T_{\mathrm{A} 2} i_{2}}{\left(Z_{\mathrm{t} 2 \mathrm{~s}}+Z_{\mathrm{t} 2 \mathrm{x}}\right)}\left(\cos Z_{\mathrm{K} 2} \varphi_{2 \mathrm{j}}+\sqrt{\lambda_{2}^{2}-\sin ^{2} Z_{\mathrm{K} 2} \varphi_{2 \mathrm{j}}}\right) \sin ^{2} Z_{\mathrm{K} 2} \varphi_{2 \mathrm{j}} \\
F_{3 \mathrm{j}}=\frac{2 T_{\mathrm{A} 2}}{\left(Z_{\mathrm{t} 2 \mathrm{~s}}+Z_{\mathrm{t} 2 \mathrm{x}}\right) \sin \beta} \sin Z_{\mathrm{K} 2} \varphi_{2 \mathrm{j}}\left(\cos Z_{\mathrm{K} 2} \varphi_{2 \mathrm{j}}+\sqrt{\left.\lambda_{1}^{2}-\sin ^{2} Z_{\mathrm{K} 2} \varphi_{2 \mathrm{j}}\right)} \sqrt{\left(Z_{\mathrm{K} 2}^{2}-1\right) \sin Z_{\mathrm{K} 2} \varphi_{2 \mathrm{j}}+\lambda_{2}^{2}}\right.
\end{array}\right.
$$

In a same manner, considering generator eccentricity error, the forces on the movable tooth $j$ in the second-stage drive can also be obtained as follows:

$$
\begin{gathered}
F_{1 \mathrm{j}}=\frac{F_{\mathrm{jj}}+F_{\mathrm{jjp}}}{\sin \beta}, \\
F_{2 \mathrm{j}}=F_{\mathrm{sj}}+F_{\mathrm{sjp}}, \\
F_{3 \mathrm{j}}=\frac{F_{\mathrm{gj}}+F_{\mathrm{gjp}}}{\sin \beta} .
\end{gathered}
$$

In the form, each equation is the same as the corresponding equation in the first-step drive, so the relevant parameters can be replaced by ones of the second-step drive for force calculation. 


\section{Results and discussion}

Using above equations, the forces on the movable tooth of the reducer are calculated (see Figs. 5-9). Here, $Z_{\mathrm{k} 1}=6$, $Z_{\mathrm{G} 1}=7, Z_{\mathrm{k} 2}=5, Z_{\mathrm{G} 2}=6, a_{1}=1.3 \mathrm{~mm}, b_{1}=16 \mathrm{~mm}, a_{2}=1.3 \mathrm{~mm}, b_{1}=16 \mathrm{~mm}, \beta=\pi / 6$. The speed ratio is 35 . The calculations are done for two situations: (1). without eccentricity error; (2). with eccentricity error of wave generator, $\Delta a=0.01 \mathrm{~mm}$. Results show:

(1). In the first stage drive, the force $F_{2 \mathrm{i}}$ from movable tooth frame is the smallest among forces $F_{1 \mathrm{i}}, F_{2 \mathrm{i}}$ and $F_{3 \mathrm{i}}$. The force $F_{3 \mathrm{i}}$ from center ring is larger than force $F_{1 \mathrm{i}}$ from wave generator. The forces $F_{1 \mathrm{i}}, F_{2 \mathrm{i}}$ and $F_{3 \mathrm{i}}$ change periodically and their change period is $\pi / Z_{\mathrm{K} 1}$. In the second stage drive, the force $F_{2 \mathrm{j}}$ from movable tooth frame is the smallest among forces $F_{1 \mathrm{j}}, F_{2 \mathrm{j}}$ and $F_{3 \mathrm{j}}$. The force $F_{3 \mathrm{j}}$ from center ring is larger than force $F_{1 \mathrm{j}}$ from wave generator. The forces $F_{1 \mathrm{j}}, F_{2 \mathrm{j}}$ and $F_{3 \mathrm{j}}$ change periodically and their change period is $\pi / Z_{\mathrm{K} 2}$. The forces $F_{1 \mathrm{j}}, \mathrm{F} 2 \mathrm{j}$ and $F_{3 \mathrm{j}}$ in the second stage drive are larger than forces $F_{1 \mathrm{i}}, F_{2 \mathrm{i}}$ and $F_{3 \mathrm{i}}$ in the first stage drive, respectively.

(2). As the eccentric distance $a_{1}$ in the first stage drive increases, the force $F_{1 \mathrm{i}}$ from wave generator reduces rapidly, the force $F_{2 \mathrm{i}}$ from movable tooth frame increases slightly, and the force $F_{3 \mathrm{i}}$ from center ring reduces significantly. It shows that the eccentric distance a1 has an important effect on the force $F_{1 \mathrm{i}}$, little effect on the force $F_{2 \mathrm{i}}$, significant effect on the force $F_{31}$.

(3). As the radius $b_{1}$ in the first stage drive increases, the force $F_{1 \mathrm{i}}$ from wave generator changes slightly, the force $F_{2 \mathrm{i}}$ from movable tooth frame decreases rapidly, and the force $F_{3 \mathrm{i}}$ from center ring reduces significantly. It shows that the radius $b_{1}$ has an important effect on the force $F_{2 \mathrm{i}}$, little effect on the force $F_{2 \mathrm{i}}$, significant effect on the force $F_{3 \mathrm{i}}$.

(4). As the eccentric distance $a_{2}$ in the second stage drive increases, the force $F_{1 \mathrm{j}}$ from wave generator reduces rapidly, the force $F_{2 \mathrm{j}}$ from movable tooth frame increases slightly, and the force $F_{3 \mathrm{j}}$ from center ring reduces rapidly as well. It shows that the eccentric distance $a_{2}$ has an important effect on the force $F_{1 \mathrm{j}}$ and $F_{3 \mathrm{j}}$, and little effect on the force $F_{2 \mathrm{j}}$. (5). As the radius $b_{2}$ in the second stage drive increases, the force $F_{1 \mathrm{j}}$ from wave generator does not change nearly, the force $F_{2 \mathrm{j}}$ from movable tooth frame decreases rapidly, and the force $F_{3 \mathrm{j}}$ from center ring reduces slightly. It shows that the radius $b_{2}$ has an important effect on the force $F_{2 \mathrm{j}}$, little effect on the forces $F_{1 \mathrm{j}}$ and $F_{3 \mathrm{j}}$.
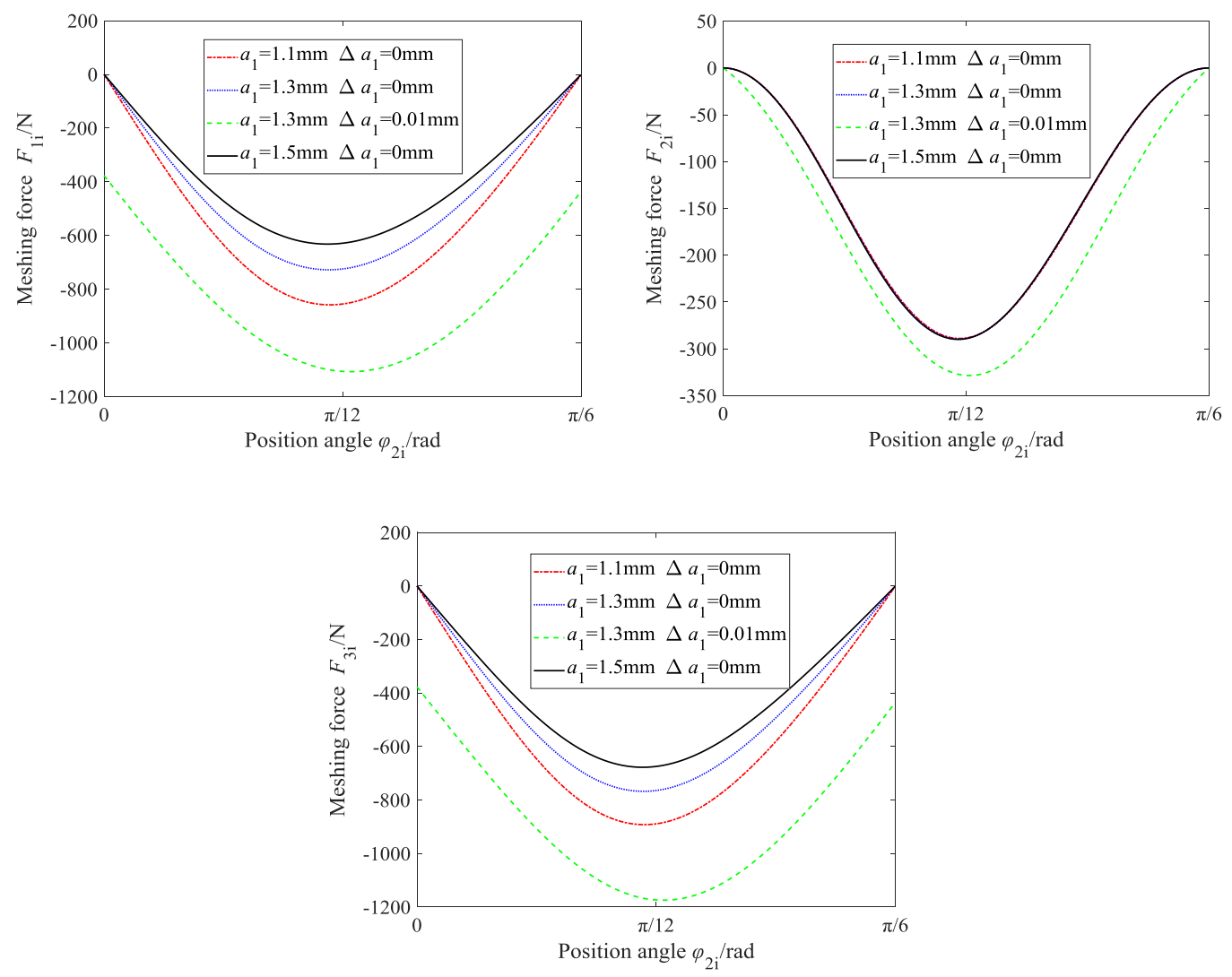

Fig. 5 Changes of the forces in the first stage drive along with $a_{1}$ and $\Delta a_{1}$. Using equations of the meshing forces, changes of the forces in the first stage drive along with eccentric distance $a_{1}$ and its error $\Delta a_{1}$ are plotted. As the 
eccentric distance $a_{1}$ is decreased and its error $\Delta a_{1}$ is increased, the meshing forces are increased.

(6). As the angle $\beta$ increases, the force $F_{1 \mathrm{i}}$ from wave generator reduces rapidly, the force $F_{2 \mathrm{i}}$ from movable tooth frame increases slightly, and the force $F_{3 \mathrm{i}}$ from center ring reduces rapidly as well. It shows that the angle $\beta$ has an important effect on the force $F_{1 \mathrm{i}}$ and $F_{3 \mathrm{i}}$, and little effect on the force $F_{2 \mathrm{i}}$.

(7) Fig. 5, Fig. 6 and Fig. 9 show the influence of eccentricity error on the meshing forces of the first-stage drive. When the eccentricity error is taken into account, the changing trend of each force with the position angle is basically unchanged. But, meshing forces of the first-stage drive are increased significantly.

When the eccentricity error is equal to $0.01 \mathrm{~mm}$, the maximum meshing force on the wave generator increases by nearly 1.4 times, the maximum meshing force on the movable tooth frame increases by nearly 1.2 times, and the maximum meshing force on the center ring increases by nearly 1.4 times. Meanwhile, at the position angles corresponding to previous zero forces, large forces occur for the wave generator and the center ring.

(8) Fig. 7 and Fig. 8 show the influence of eccentricity error on the meshing forces of the second-stage drive. When the eccentricity error is considered, the changing trend of each force with the position angle is basically unchanged as well. But, meshing forces of the second-stage drive are increased more obviously.

When the eccentricity error is equal to $0.01 \mathrm{~mm}$, the maximum meshing force on the wave generator increases by nearly 2 times, the maximum meshing force on the movable tooth frame increases by nearly 1.6 times, and the maximum meshing force on the center ring increases by nearly 2 times. On the whole, eccentricity error has a more obvious effect on the meshing force of the second stage drive than that of the first-stage drive, and higher requirements are put forward for the second-stage manufacturing accuracy of eccentricity.
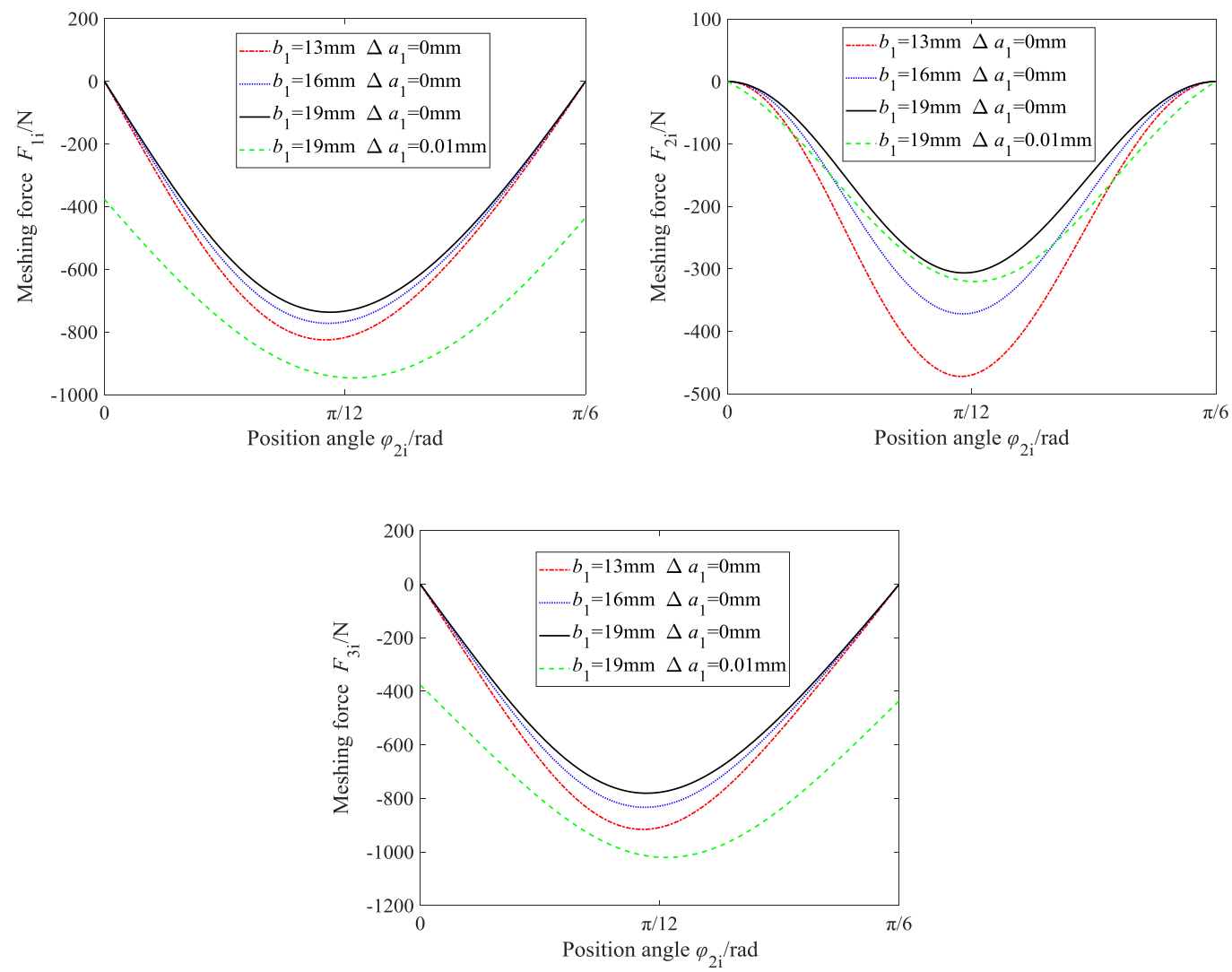

Fig. 6 Changes of the forces in the first stage drive along with $b_{1}$ and $\Delta a_{1}$. Using equations of the meshing forces, changes of the forces in the first stage drive along with the radius $b_{1}$ and eccentric distance error $\Delta a_{1}$ are plotted. As the radius $b_{1}$ is decreased and its error $\Delta a_{1}$ is increased, the meshing forces are increased. 

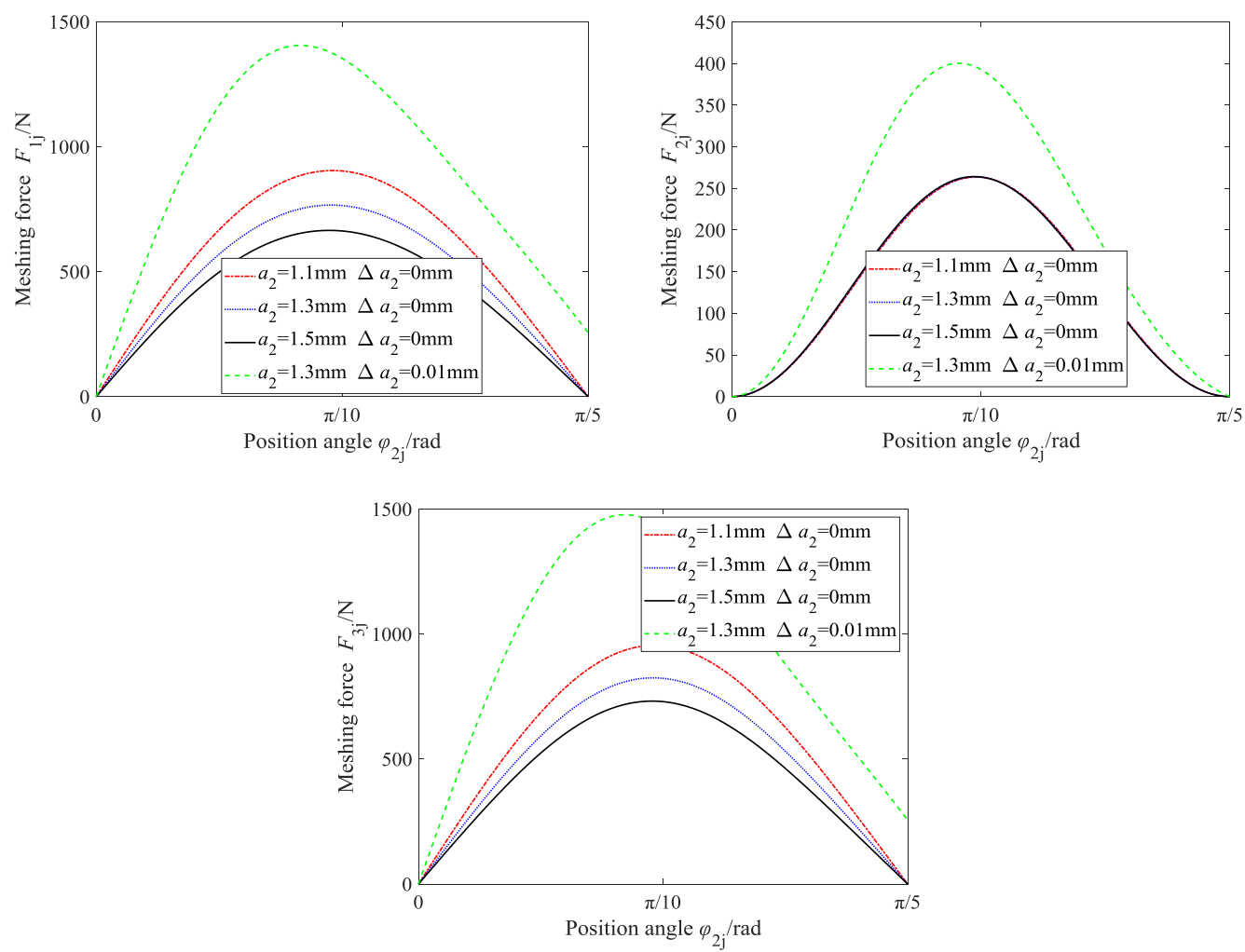

Fig. 7 Changes of the forces in the second stage drive along with $a_{2}$ and $\Delta a_{2}$. Using equations of the meshing forces, changes of the forces in the second stage drive along with the along with eccentric distance $a_{2}$ and its error $\Delta a_{2}$ are plotted. As the eccentric distance $a_{2}$ is decreased and its error $\Delta a_{2}$ is increased, the meshing forces are increased.
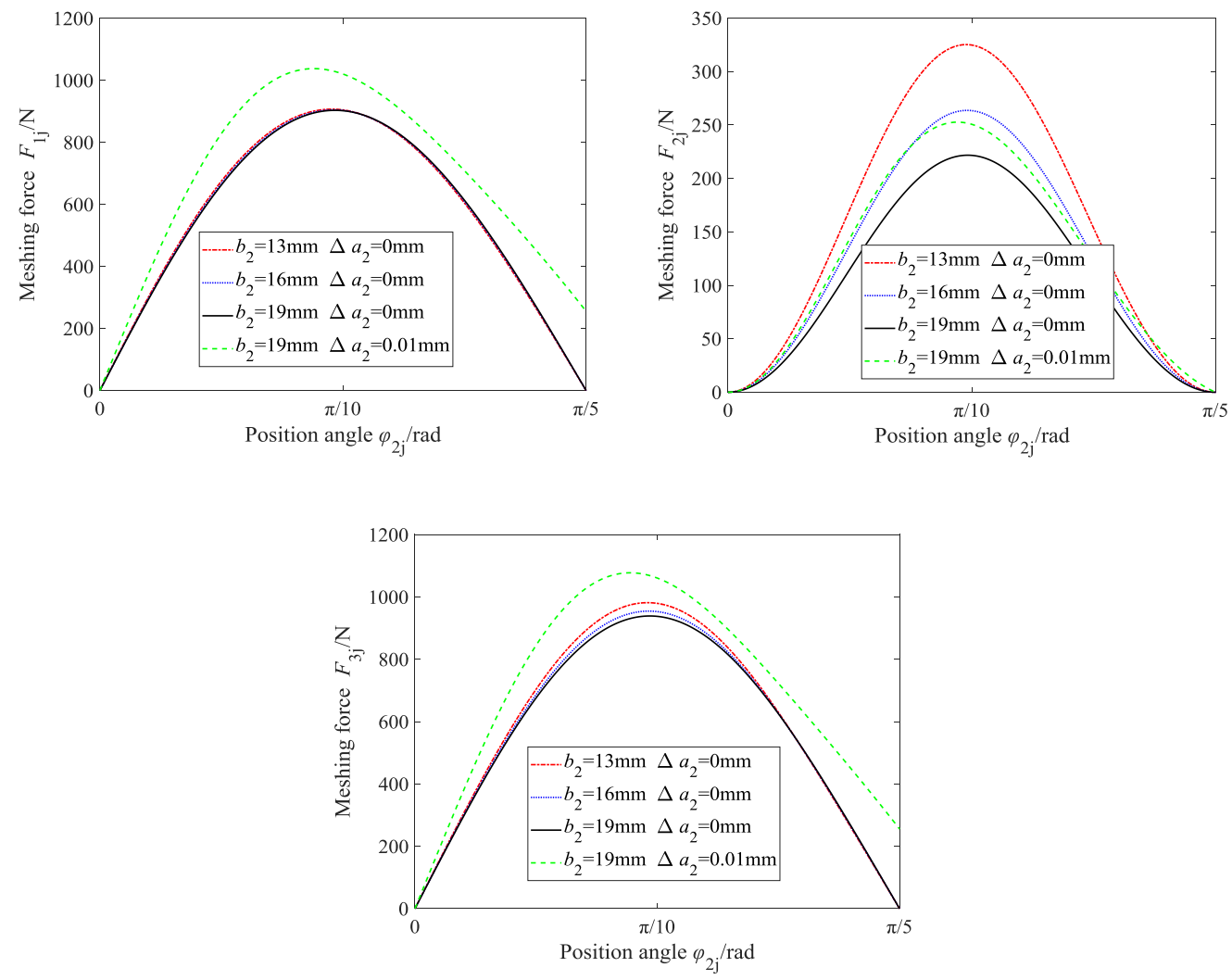

Fig. 8 Changes of the forces in the second stage drive along with $b_{2}$ and $\Delta a_{2}$. Using equations of the meshing forces, changes of the forces in the second stage drive along with the radius $b_{2}$ and eccentric distance error $\Delta a_{2}$ are plotted. As the radius $b_{1}$ is decreased and its error $\Delta a_{1}$ is increased, the meshing forces are increased. 

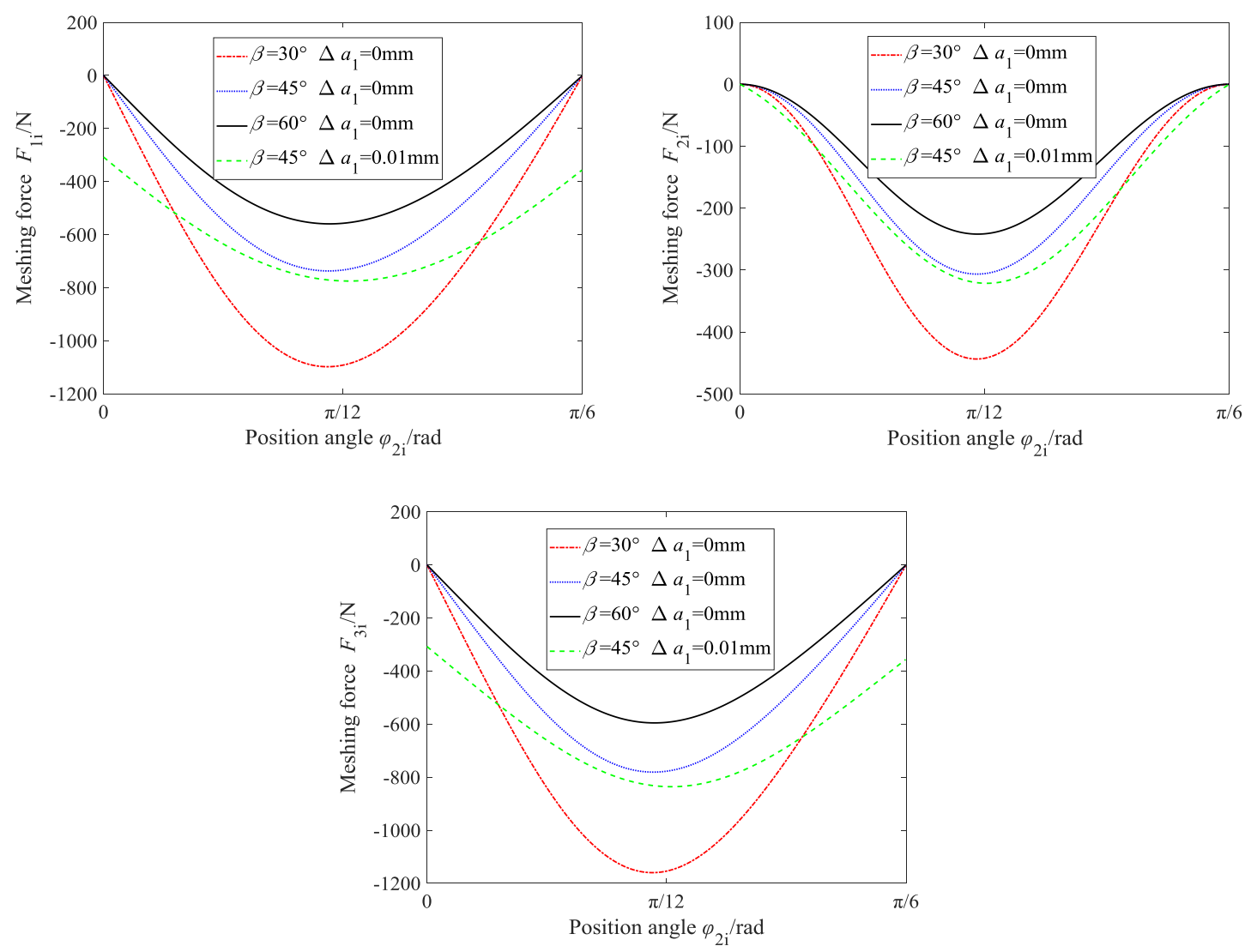

Fig. 9 Changes of the forces in the first stage drive along with $\beta$ and $\Delta a_{1}$. Using equations of the meshing forces, changes of the forces in the first stage drive along with angle $\beta$ and its error $\Delta a_{1}$ are plotted. As the angle $\beta$ is decreased and its error $\Delta a_{1}$ is increased, the meshing forces are increased.

Software UG is an interactive CAD/CAM (computer-aided design and computer-aided manufacturing) system produced by Siemens PLM Software Company. Software UG is used to establish 3D models of the key part for the movable tooth reducer, as shown in Fig. 10. Parameters of the example reducer are shown in Table 1.

Table 1 Parameters of the example reducer

\begin{tabular}{c|c}
\hline parameters & values \\
\hline wave number of first-stage center ring $Z_{\mathrm{K} 1}$ & 6 \\
number of first-stage steel balls $Z_{\mathrm{G} 1}$ & 7 \\
Radius of movable tooth $r(\mathrm{~mm})$ & 6 \\
first-stage eccentric distance $a_{1}(\mathrm{~mm})$ & 1.3 \\
first stage radius of the base circle $b_{1}(\mathrm{~mm})$ & 16 \\
wave number of second-stage center ring $Z_{\mathrm{K} 2}$ & 5 \\
number of second-stage steel balls $Z_{\mathrm{G} 2}$ & 6 \\
second-stage eccentric distance $a_{2}(\mathrm{~mm})$ & 1.3 \\
second stage radius of the base circle $b_{2}(\mathrm{~mm})$ & 16 \\
speed ratio $i_{s}=\frac{z_{\mathrm{K} 2} Z_{\mathrm{G} 1}}{Z_{\mathrm{K} 2} Z_{\mathrm{G} 1}-Z_{\mathrm{G} 2} Z_{\mathrm{K} 1}}$ & 35 \\
\hline
\end{tabular}




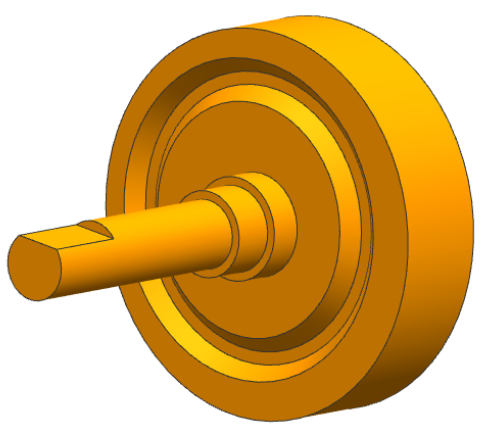

a)

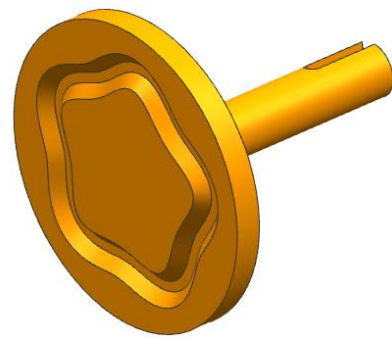

c)

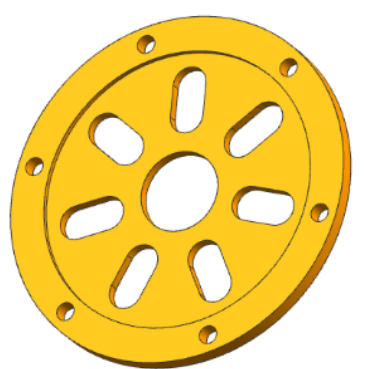

d)

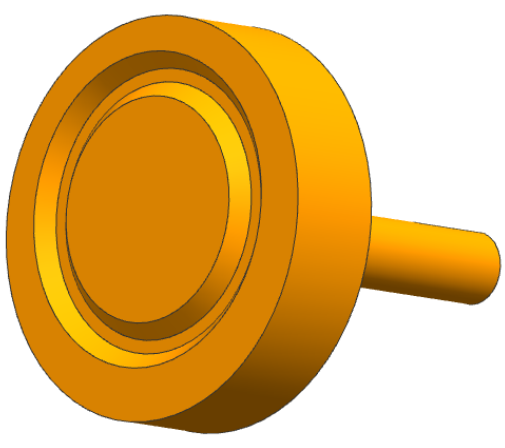

b)

Fig. $103 \mathrm{D}$ models of the key part for the reducer. a). wave generator $\mathrm{H} 1$; b). wave generator $\mathrm{H} 2$; c). output d). movable tooth frame G1; e). movable tooth frame G2.

The established 3D parts are assembled, and the "interference test" in "execution analysis" is applied to check whether there is body interference in the assembly, and no interference is found. Assembly is completed (see Fig.1a), and the explosion model of main parts is shown in Fig.1b. In the assembled 3D model, the linkage and motion pair is set. The setting steps are as follows: application module $\rightarrow$ simulation $\rightarrow$ motion $\rightarrow$ assembly in the motion navigator $\rightarrow$ simulation. After the 3D model is assembled, the first-step center ring K1 and the outer shell are set as fixed pairs. The second-step center ring K2 and the input shaft are set as rotation pairs that rotate around the center of the first central ring. The angular velocity of the input shaft is $30 \mathrm{rad} / \mathrm{s}$. The sliding pair is set between the first-step steel ball and the first-step movable tooth frame G1, and between the second-step steel ball and the second-step movable tooth frame G2. The second-step movable tooth frame G2 is set as rotation pair that rotates around the center of the first central ring. The second-step movable tooth frame is fixed with the first-step movable tooth frame. By the dot-line pair constraints, the ball center of the first-step steel balls is restrained on the track center line of the first-step center ring $\mathrm{K} 1$ and the track center line of the left end of the input shaft. By the dot-line pair constraints, the ball center of the second-step steel balls is restrained on the track center line of the output shaft and the track center line of the right end of the input shaft. After setting the above constraints, the calculate time is set to be $180 \mathrm{~s}$. The step number per second is set to be 30 . The total step number is set to be 5400. After that, the calculation is begun and 5400 data are obtained which are exported to obtain scatter image as shown in Fig.11.

Frequency histogram distribution is performed on 5400 groups of data. Its mathematical expectation is equal to 0.8687. Thus, the speed ratio of the drive can be obtained, it is $30 / 0.8687=34.53$. Considering the inevitable calculative errors in the simulation process, it could be known that the true speed ratio of this new reducer is 35 , which is equal to the design value and it illustrates the rationality of the structure and the correctness of the motion principle.

Fig. 11 shows that fluctuating amplitude of the speed ratio is about $10 \%$. It is caused by computational errors in the processing of complex systems using UG software. So, the speed ratio of the reducer can be determined by the average value of the simulated speed ratio. The speed ratio error in engineering is caused by design error, manufacturing error and assembly error. It influences the motion precision and stationary precision of the reducer. The design error must be avoided. The manufacturing error and assembly error could be reduced by accuracy design of the reducer.

When the input shaft speed is $30 \mathrm{rad} / \mathrm{s}$, the theoretical output speed should be the ratio of the input speed to the speed ratio: $30 / 35=0.857 \mathrm{rad} / \mathrm{s}$. When the eccentricity error of the wave generator does not exist, the simulation data is 
derived and the scatter diagram is drawn as shown in upper figure of Fig. 11. The expected value of the simulated output shaft speed is obtained as follows: $E\left(\omega_{3}\right)_{1}=0.8687$. Corresponding variance is $D\left(\omega_{3}\right)_{1}=0.052$. Thus, the relative error of the speed ratio is

$$
E_{1}=\frac{\left|E\left(\omega_{3}\right)_{1}-\omega_{1} / i_{s}\right|}{\omega_{1} / i_{s}} \times 100 \%=\frac{0.8687-0.857}{0.857} \times 100 \%=1.36 \% .
$$

This error is actually caused by the calculation error of the simulation software.

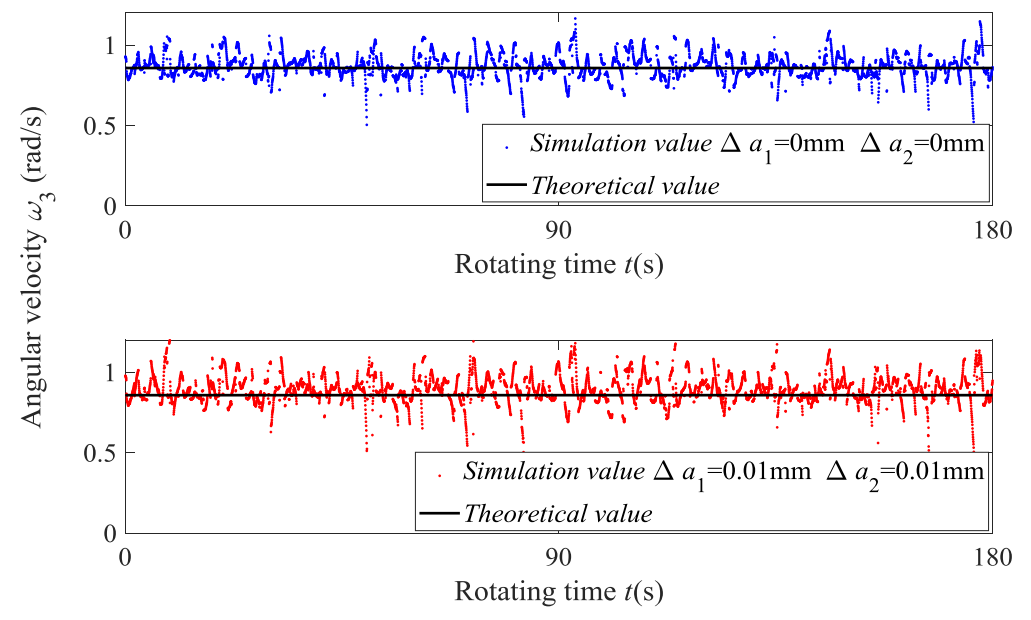

Fig. 11 Change curve of its output speed with time. Using software UG, Change curves of its output speed for the reducer with time are plotted for two situations with or without eccentric distance error. As the eccentric distance error occurs, fluctuation of the output speed for the reducer becomes large.

When the eccentricity error of the wave generator is considered (here, the eccentricity error is taken to be $\Delta a_{1}=0.01 \mathrm{~mm}$ and $\Delta a_{2}=0.01 \mathrm{~mm}$ ), the simulation data is derived and the scatter diagram is drawn as shown in lower figure of Fig. 11. The expected value of the simulated output shaft speed is obtained as follows: $E\left(\omega_{3}\right)_{2}=$ 0.8915 , corresponding variance is $D\left(\omega_{3}\right)_{2}=0.073$. Thus, the relative error of the speed ratio is

$$
E_{2}=\frac{\left|E\left(\omega_{3}\right)_{2}-{ }^{\omega_{1}} / i_{s}\right|}{\omega_{1} / i_{s}} \times 100 \%=\frac{0.8915-0.857}{0.857} \times 100 \%=4.03 \%
$$

Subtracting the above simulation error, the speed ratio error caused by the eccentricity error of $0.01 \mathrm{~mm}$ is $4.03 \%-1.36 \%=2.67 \%$. The eccentricity error will affect the speed ratio accuracy of the drive, and affect the accuracy and stability of the transmission process. Eccentricity errors should be minimized during design, fabrication and assembly as far as possible.

\section{Conclusion}

In this paper, a planar two-stage tooth reducer closed by input shaft is proposed, which has the advantages of large speed ratio and compact axial size. Through the analysis of the motion transfer flow, the equation for calculating the speed ratio of the reducer is given. Using the equation, the tooth number relationship for realizing large speed ratio is determined. The power flow analysis of the reducer is carried out, and the equation of power flow calculation is given by which the conditions for generating closed power are determined. The output torque of the reducer and the force on the meshing pair are investigated, and the changes of the forces on the meshing pair with the parameters are analyzed. The three-dimensional design and motion simulation of the reducer are carried out. According to the simulation, the speed ratio of the given parameters is obtained, which is consistent with the theoretical design and verifies the feasibility of the proposed reducer. 


\section{Acknowledgment}

This project is supported by National key R \& D Program of China (No. 2018YFB1304800) and the Hebei Province Natural Science Foundation in China (No.E2017203021).

\section{References}

Furuta, K., Eccentric-oscillating gear device, DE102016201055A1(2016).

Нъезруков, В., О зубчтой зволъвентной передэче составленной изконический колес с лроизвольньым располжением и хосей известия Вузов, Машинзстроение, No.6(1963), pp.12-15.

Imase, K., Ball-rolling type torque transmission device, US , US5683323A (1997).

Kennedy, C., and Desai, J., Modeling and control of the Mitsubishi PA-10 robot arm harmonic drive system, IEEE-ASME Transactions on Mechatronics, Vo.10, No.3(2005), pp.263 -274.

Keith, S., Subtractive and additive differential gear reduction system, US, US4338830A (1982).

Li, C., Xing, J., and Fang, J. Numerical analysis on chaotic vibration of drive system for a movable tooth piezoelectric motor, Shock and Vibration, Vo.6, No.3(2017), pp.42-46.

Liang, Y. and Xu, L., Free vibration for an electromagnetic harmonic movable tooth drive system, Open Mechanical Engineering Journal, Vol.9, No.1(2015), pp.15-21.

Liang, S. and Li, L., Coupled thermo-elastic deformation of swing movable teeth transmission, Journal of Southwest Jiaotong University, Vol.52, No.3(2017), pp.607-611.

Li, C., Xing, J. and Fang, J., Numerical analysis on chaotic vibration of drive system for a movable tooth piezoelectric motor, Shock and vibration, (2017), Paper No.3216010.

Litvin, F.L. Gear Geometry and Applied Theory. Publisher: Cambridge University Press (1994).

Li, Z., Melek, W., and Clark, C., Decentralized robust control of robot manipulators with harmonic drive transmission and application to modular and reconfigurable serial arms, Robotica, Vo.27, No.2(2009), pp.291 - 302.

Mo, S., Zhang,Y., and Wu, Q., Load sharing characteristics of RV transmission mechanism in robot, Mechanisms and Machine Science, Vo.36(2016), pp.977-987.

Nishibe, S., Mitsufuji, S. and Nishtani, Y., Eccentric oscillating reduction gear for joint drive of robot, JP2014161952A (2014).

Nam, W., Shin, J. and Oh, S., Design of thin plate-type speed reducers using balls for robots, Journal of Mechanical Science and Technology, Vol.27, No.2(2013), pp.519-524L.

Platek,V., Universal joint and driveshaft design manual GB Amold, Society of Automotive Engineers, Vo.3, No.58(2016), pp.5-6.

Sapsalev, AV., Comparison of the linear tachograms of cyclic gearless electric drives, Vestn Mashinostr, No.3(2004), pp.12-15.

Sapsalev, AV., Optimizing cyclic gearless electric drives with a reduced-speed section, Allerton Press Inc, Vol.5-6, No.32(2012), pp.438-443.

Terada, H., The development of gearless reducers with rolling balls, Korean Society of Mechanical Engineers, Vo.1, No.24(2016), pp.185-195.

Terada, H. and Imase, K., Fundamental analysis of a cycloid ball reducer ( $5^{\text {th }}$ Report)-Development of a two stage type reduction mechanism, JSPE, Vol.75, No.12(2009), pp.1418-1422.

Terada, H., The development of gearless reducers with rolling balls, Korean Society of Mechanical Engineers, Vol.24, No.1(2010), pp.185-195.

Vassileva, D., Kiyosawa, Y., and Suzuki, M., Sensorless torque control for a robot with harmonic drive reducers, Mechanics based design of structures and machines, Vo.39, No.2(2011), pp. 253 - 267.

Wu, J., Zhou, X, and Zhang, H., The FEA of New Type Roller Movable Teeth Reducer, Applied Mechanics and Materials, Vo.152-154(2012), pp.603-608.

$\mathrm{Xu}, \mathrm{L}$. and Wang, W., Quasi-static analysis of forces and stress for a novel two-step movable tooth drive, Mechanics based design of structures and machine, Vo.46, No.3(2018), pp.285-295.

$\mathrm{Xu}, \mathrm{L}$. and Men, M., Meshing efficiency for sinusoidal movable tooth drive, Journal of Advanced Mechanical Design, Systems, and Manufacturing, Vo.13, No.4(2019), DOI: 10.1299/jamdsm.2019jamdsm0081. 
Yang, H., Xu, M., Li, W., Design and implementation of a soft robotic arm driven by SMA coils, IEEE Transactions on Industral Electronics, Vo.66, No.8(2019),pp.6108-6116.

Yang, R., Li,F., and Zhou, Y., Nonlinear dynamic analysis of a cycloidal ball planetary transmission considering tooth undercutting, Mechanism and Machine Theory, Vo.145(2020),103694.

Yi, Y., and An, Z., Research on Digital Design and Manufacture Technology of Rolling Swing Movable Teeth Transmission, Applied Mechanics and Materials, Vo.86(2011), pp.370-373. 